\title{
Performance Study of Hybrid Wireless Mesh Protocol (HWMP) for IEEE 802.11s WLAN Mesh Networks
}

\author{
S. M. S. Bari, F. Anwar, M. H. Masud \\ Department of Electrical and Computer Engineering \\ International Islamic University Malaysia \\ Kuala Lumpur, Malaysia \\ sms_bari@yahoo.com,farhat@iium.edu.my,masuduia@yahoo.com,
}

\begin{abstract}
Wireless Mesh Network (WMN) have been envisioned as an important solution to the next generation wireless networking which can be used in wireless community networks, wireless enterprise networks, transportation systems, home networking and last-mile wireless internet access. Many proprietary mesh solutions were developed by individual vendor but in order to interoperability; IEEE forms a task group called IEEE 802.11s to develop an integrated mesh networking solution. Hybrid Wireless Mesh protocol (HWMP) and airtime metrics as default routing protocol and routing metrics set by the task group. There is few test bed and many simulation studies have been done to evaluate the performance of the HWMP protocol with the assumption of unique type of flow with fixed packet size and packet rate. However, real networks carry a diverse application (video, voice, FTP, Email etc) with different characteristics (packet size, data rate). In this paper, we are investigated and analyzed the performance of HWMP protocol under such heterogeneous application characteristics.
\end{abstract}

Keywords- Routing protocol, Hybrid wireless Routing Protocol (HWMP), Wireless Mesh Network (WMN), IEEE 802.11s

\section{INTRODUCTION}

Wireless mesh networks (WMN) have been emerged to address the limitations of traditional wireless networking. It is a special kind of multihop wireless network that consists of mesh routers and mesh clients [1]. Typically, mesh routers are static and power-enabled and they form a wireless backbone for the WMNs while connected with the wired networks to provide multi-hop wireless internet connectivity to the mesh clients. Mesh clients may be mobile and they can access the network via mesh routers or directly by forming a mesh with each other.

WMN is a fast-growing wireless technology that may serve as a rich set of applications like wireless community networks, wireless enterprise networks, transportation systems, home networking and last-mile wireless internet access.[2]. Figure-1 shows an example of wireless mesh network. Mesh Access Points (MAP) are the point of attachment for the mesh clients like Wi-Fi network. However, Mesh Points (MP) act as router which forward the traffic based on their routing (path selection) table and provide mesh services. Mesh Portal Points (MPPs) provides the inter-networking connectivity with other subnet or Basic Service Set (BSS).

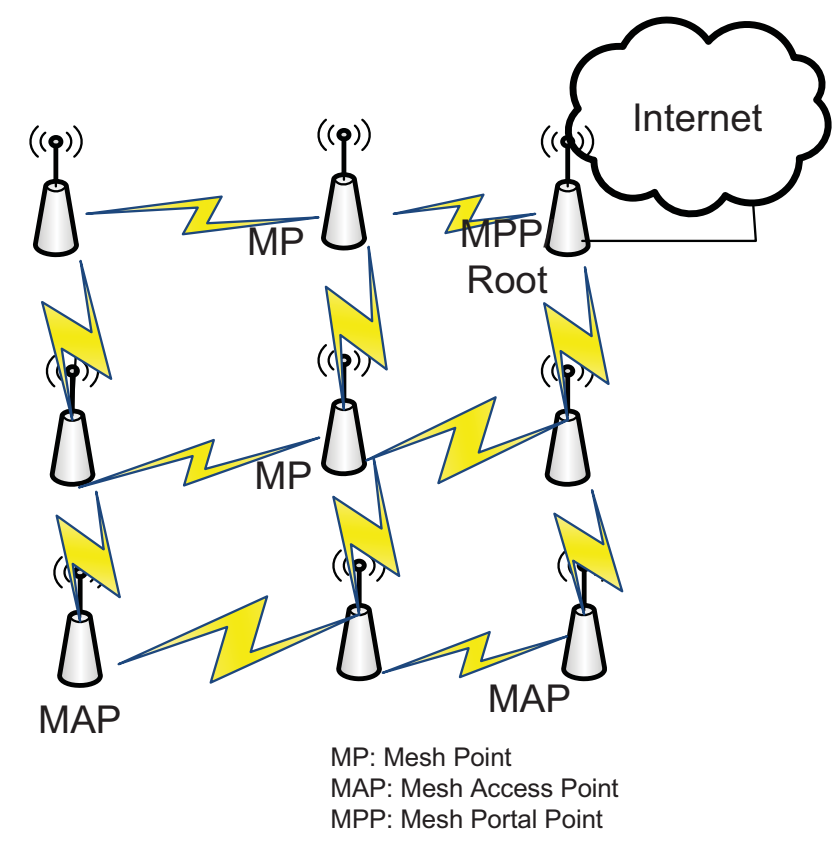

Figure 1. Typical example of Wireless Mesh Network

The present 802.11 based wireless networks rely on wired infrastructure to carry the user's traffics. However, this dependency on wired infrastructures is costly and inflexible as wireless local area network (WLAN) coverage cannot be extended beyond the back-haul deployment. WLANs can extend its capability using the mesh concept. Consequently, wireless mesh networks (WMNs) inherently hold the promise of a solution. However, performance of a WMN is largely dependent on the design of routing protocols and the associated routing metrics. The routing protocol selects the best path between the source and destination based on the routing metrics. Existing routing protocols used in WMNs rely on the IP layer and use hop count to enable multihop communication and do not provide an inherently wireless solution. To overcome this, IEEE form a task group called IEEE 802.11s [3] to develop an integrated mesh networking solution. The standardization process is going on but main traits are set. The task group set hybrid wireless mesh protocol (HWMP) [4] as 
default routing protocol at MAC layer and air time [5] metric is default routing metrics.

In literature[6,7,8,9], the performance evaluation of HWMP protocol and airtime routing metric are generally done by considering a unique type of flow with fixed packet size and packet rate. However, the real Wireless Mesh Network scenario is quite different. There will be various types of simultaneous traffic flow with different characteristics (different application, i.e. voice, video, email, FTP, HTTP) exist in a WMN. In this paper we investigate the performance of HWMP protocol under such heterogeneous applications or traffic conditions.

The rest of the paper is organized as follows: Section II presents the state of the art of the routing protocol and routing metrics used in WMN. Section III describes the HWMP protocol in brief. Simulation for reactive and proactive protocol considering different parameters has done in section IV. In section V, result and discussion are analyzed of the simulations. Finally Section VI summarizes the paper with presenting the future work of this research.

\section{BACKGROUND}

Recently, routing protocols and algorithms for wireless mesh networks have been extensively examined [1].Wireless Mesh Networks have many common feature with mobile adhoc networks. Thus many of the routing protocols used in wireless mesh networks primarily derived from Mobile Adhoc Networks (MANETs). For Example, Microsoft mesh network [10] was based on dynamic source routing (DSR), Firetide mesh router [11] used topology broadcast based on reverse path forwarding (TBRPF) protocol, MIT's RoofNet [12] used extremely opportunistic routing (ExOR), IEEE 802.11s used Hybrid Wireless Mesh Protocol (HWMP) [4] which is based on Adhoc On demand distance vector (AODV) etc.

Routing protocol used in wireless mesh network can be categorized as proactive, reactive and hybrid. In proactive routing, a routing path established between two nodes before any flow of data traffic. In fact, routing protocols maintain routing table to keep routes to all destinations, regardless of whether or not these routes are needed. To maintain the routing table up to date, a node periodically send control information which may cause valuable bandwidth wasting. However, these protocols facilitated a node to get quick route information and instantly start the flow of data traffic. Examples of proactive routing protocols are: Optimized Link State routing protocol (OLSR), Destination-sequenced distance vector routing protocol (DSDV) and the Wireless Routing protocol (WRP).

In reactive routing protocols, a path is established only when the source needs to communicate with a destination. This certainly reduces the routing overhead but introduces a route setup delay. Reactive protocols can be classified into two categories: source routing and hop-by-hop routing. In source routed on-demand protocols [13], each data packets carry the complete source to destination address. In hop-by-hop [14], each data packet only carries the destination address and the next hop address. A number of different reactive routing protocols have been proposed to increase the performance of reactive routing such as Dynamic Source Routing Protocol
(DSR), Ad hoc On-demand Distance Vector (AODV) and the Dynamic MANET On-demand (DYMO).

Hybrid routing protocols combine both reactive and proactive routing to increase the overall scalability of routing in networks. The basic idea behind hybrid routing protocols is to use proactive routing mechanisms in some areas of the network at certain times and reactive routing for the rest of the network [15]. A number of different hybrid routing protocols have been proposed to increase the performance of routing such as Zone Routing Protocol (ZRP), Distributed spanning trees based routing protocol (DST) and Zone-based hierarchical link state (ZHLS).

However, the aforementioned existing routing protocols used in WMNs rely on the IP layer (layer 3) to enable multihop communication and cannot capture the nature of the wireless link accurately [16]. Since wireless links are more vulnerable than wired links, a multihop routing protocol operating in a wireless environment must account for the nature of the wireless links. To realize the benefits of MAC-based WMN routing, IEEE form IEEE 802.11 Task Groups to develop an integrated mesh networking solution. The standard is not finalized yet but main features are set. The task group set hybrid wireless mesh protocol (HWMP) as default routing protocol and air time metric is default routing metrics. The optional routing protocol is based on link state routing and is called radio aware optimized link state routing (RA-OLSR).

HWMP protocol use airtime routing metric default as specified in the IEEE802.11s draft standard. It reflects the amount of channel resource consumed for transmitting a frame over a particular link. The airtime cost $\left(\mathrm{C}_{\mathrm{a}}\right)$ for each link is calculated as

$$
\mathrm{C}_{\mathrm{a}}=\left[\mathrm{O}_{\mathrm{ca}}+\mathrm{O}_{\mathrm{p}}+\mathrm{B}_{\mathrm{t}}\right]\left[\mathrm{r} /\left(1-\mathrm{e}_{\mathrm{pt}}\right)\right]
$$

Where $\mathrm{O}_{c a}$ is the channel access overhead, $\mathrm{O}_{\mathrm{p}}$ is the protocol overhead, $B_{t}$ is the number of bit in the test frame, $r$ is the bit rate in Mbit/s and $\mathrm{e}_{\mathrm{pt}}$ is the frame error rate.

Many other routing metrics also developed to capture and optimize the performance parameter of the routing protocol use in WMNs beyond the traditional hop count method widely used for wired network. Expected Transmission Count (ETX) [17] is one of the early routing metrics developed for wireless network to capture the link quality by estimating the number of transmission attempts required for a successful transmission on a particular wireless link.

However, it does not consider the bandwidth (different transmission rate) of the wireless link. Also, it calculates the packet error rate using periodically broadcast a probe packet which can not accurately measure the link quality because the probable packet is much smaller than the actual data packets. Furthermore, ETX does not consider the interflow and intraflow interference of the link.

Weighted Cumulative Expected Transmission Time (WCETT) proposed by Draves et al. [18] as a path metric for routing in multi-radio multi-channel WMNs. WCETT is based on ETT.

$\mathrm{ETT}=\mathrm{ETX} * \mathrm{~S} / \mathrm{B}$, (where $\mathrm{S}$ is the packet size and $\mathrm{B}$ is the bandwidth), an extended version of ETX considering the 
transmission time of the link. However ETT does not consider the presence of multiple channels and multiple radios. To solve this issue, WCETT is proposed and calculated as:

$$
\mathrm{WCETT}=(1-\beta) \sum_{i=1}^{n} E T T i+\beta \max (\mathrm{Xj})
$$

Where $\beta \max (\mathrm{Xj})$ calculate the bottleneck channel of a given routing path. However, it cannot be applied in single radio multichannel operation because broadcast probe message cannot be sent on different channel of the same radio simultaneously. Also it does not consider the interflow and intraflow interference of the link.

Metric of Interference and Channel Switching (MIC) [19] proposed by Yang et al. that incorporates both inter and intra channel interference. However, it adds significant overhead and may degrade the routing protocol performance.

PerHop RTT [20] and Per-Hop Packet Pair Delay [21] is developed to address the traffic load, queuing delay in two nodes on the link. But their performance is highly dependent on traffic load which can easily lead to route instability. Also, these metrics do not consider the link quality. Investigating the fact that each routing metrics capture only one or two performance parameters (delay, packet loss) of the network, some researchers try to integrate two or three routing metrics together to improve the performance of the routing protocol. Arafatur Rahman et. al [22], proposed an integrating multiple metrics combining ETX, RTT and Hop Count and incorporate it into AODV which improves the packet delivery ratio, throughput and end to end delay of the protocol.

However, the above mentioned routing metrics except Air time metrics, try to capture link layer performance parameter by using a procedure in the network layer. Summary of routing metrics used in wireless mesh networks are given in the following table:

TABLE1. ROUTING METRICS USED IN WMN

\begin{tabular}{|l|l|l|}
\hline $\begin{array}{l}\text { Routing } \\
\text { metrics }\end{array}$ & Best path selection Criteria & Operating Layer \\
\hline $\begin{array}{l}\text { Hop } \\
\text { Count }\end{array}$ & No. of Hops & Network \\
\hline ETX & Packet loss, Retransmission count & Network \\
\hline ETT & $\begin{array}{l}\text { Packet loss + Retransmission count }+ \\
\text { link bandwidth }\end{array}$ & Network \\
\hline WCETT & $\begin{array}{l}\text { Packet loss + link bandwidth }+ \\
\text { Retransmission count }+ \text { Bottleneck of } \\
\text { the link }\end{array}$ & Network \\
\hline AirTime & $\begin{array}{l}\text { Resource consumed by a packet to a } \\
\text { link }\end{array}$ & Link layer \\
\hline $\begin{array}{l}\text { PerHop } \\
\text { RTT }\end{array}$ & Delay, traffic load & Network \\
\hline
\end{tabular}

\section{HWMP PROTOCOL}

HWMP [4] is a hybrid routing protocol of on demand (reactive) routing and proactive tree based routing. Reactive part of HWMP is based on RM-AODV (Radio-Metric Ad hoc On Demand Distance Vector) which is an adaption of the AODV (Ad hoc On Demand Distance Vector) routing. Four control messages were specified for HWMP: root announcement (RANN), path request (PREQ), path reply (PREP), and path error (PERR). Except for PERR, all control messages contain three important fields: destination sequence number (DSN), time-to-live (TTL), and metric. DSN and TTL can prevent the count to infinity problem, and the metric helps to find a better routing path rather than just using hop count. The entire routing protocol is built based on these control messages.

When a node has data to send a certain destination, it broadcasts a PREQ (Path Request) message that contains the MAC address of the destination. Every PREQ message includes a unique sequence number that is used to determine the freshness of the PREQ messages at the receiver. When the destination node receives the PREQ message, it checks its freshness and then it updates its reverse path towards the source. The destination then creates a PREP (Path Reply) message which is afterwards unicast towards the source. Intermediate MPs receiving the PREP message update their forward path towards the destination, update the routing metric, and then forward the updated RREP towards the source.

The HWMP proactive mode is a tree based routing centered on a root node which may be the internet gateway. There are two methods available to build the proactive tree: Proactive PREQ (path request) and Proactive RANN (route announcement).

In Proactive PREQ, a root node periodically broadcast PREQ message with unique sequence number. The other node (MPs) receives the PREQ, record the routing metrics, update the PREQ (TTL, Hop Count, Path metrics) and rebroadcast it and create a reverse path towards root node. Forward path is established when Proactive PREP flag in the PREQ is set 1 by the root node. Receiving MP unicast a RREP to the root so that a bidirectional path is available proactively. If PREP flag is not set, no PREP is sent in response to PREQ. Forward path is established only when there is data in a MP to send. This is done because maintains proactive path to the root but minimize the routing overhead.

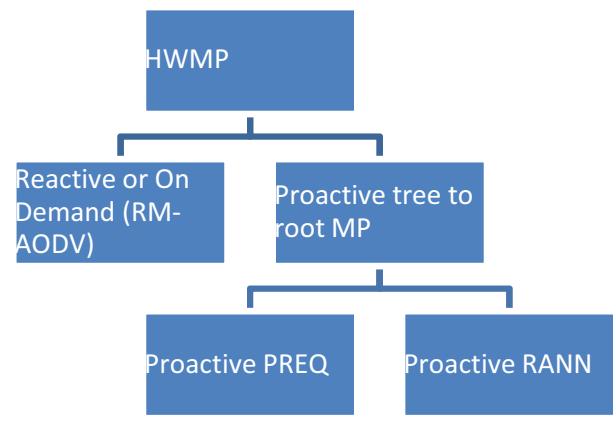

Figure 2. Classification of HWMP protocol.

In the proactive RANN method, the root MP is periodically broadcast an RANN message with increasing sequence number into the network. This is only used to disseminate the path metrics but will not create or update the routing table. When an MP needs to create/update a path to the root, it sends a unicast PREQ message to the root and set Destination Only flag. After 
receiving PREQ, the root MP replies a PREP message to the originating MP and a bidirectional path is established.

\section{SiMULATION SCENARIO}

Qualnet 5.1[23] network simulator is used to evaluate the performance of HWMP protocol. Simulation parameters are given in the following table:

\section{TABLE 2. PARAMETER USED IN SIMULATION}

\begin{tabular}{|l|l|}
\hline Parameter & Value \\
\hline Area & $1000 * 1000$ meter \\
\hline No of Nodes & 9 \\
\hline Radio Type & $802.11 \mathrm{~b}$ \\
\hline Data Rate & $2 \mathrm{Mbps}$ \\
\hline Data Link Layer Protocol & $802.11 \mathrm{~s} \mathrm{MAC}$ \\
\hline Channel Frequency & $2.4 \mathrm{GHz}$ \\
\hline No. of Channel & 1 \\
\hline Path loss Model & Two Ray \\
\hline Shadowing Model & Constant \\
\hline Antenna Model & Omni directional \\
\hline Simulation Time & $250 \mathrm{~s}$ \\
\hline Routing Protocol & $\begin{array}{l}\text { HWMP ( Proactive PREQ and } \\
\text { Reactive) }\end{array}$ \\
\hline
\end{tabular}

TABLE 3. APPLICATION TYPE AND PACKET SIZE

\begin{tabular}{|l|l|l|l|}
\hline $\begin{array}{l}\text { Application } \\
\text { Type }\end{array}$ & $\begin{array}{l}\text { Packet Size } \\
\text { (Byte) }\end{array}$ & $\begin{array}{l}\text { Packet } \\
\text { Interval }\end{array}$ & Duration \\
\hline CBR & 512 & $10 \mathrm{~ms}$ & $80 \mathrm{~s}$ \\
\hline VoIP & 160 & $20 \mathrm{~ms}$ & $80 \mathrm{~s}$ \\
\hline FTP & 1460 & & $60 \mathrm{~s}$ \\
\hline HTTP & variable & random & $20 \mathrm{~s}$ \\
\hline $\begin{array}{l}\text { Video } \\
\text { Streaming }\end{array}$ & 512 & $1 \mathrm{~ms}$ & $20 \mathrm{~s}$ \\
\hline
\end{tabular}

We used three different quantitative measures (throughput, end-to-end delay and jitter) to compare the performance of HWMP protocol, both for proactive and reactive part. These are calculated as follows:

Throughput $=($ total bytes received $* 8) /($ time last packet received - time first packet received), where the times are in seconds.

Average end-to-end delay $=($ Total of transmission delays of all received packets) / (Number of packets received), Where, transmission delay of a packet $=$ time packet received at server - time packet transmitted at client, where the times are in seconds.

Average jitter $=($ total packet jitter for all received packets $)$ / (number of packets received - 1) Where, packet jitter = transmission delay of the current packet - transmission delay of the previous packet.

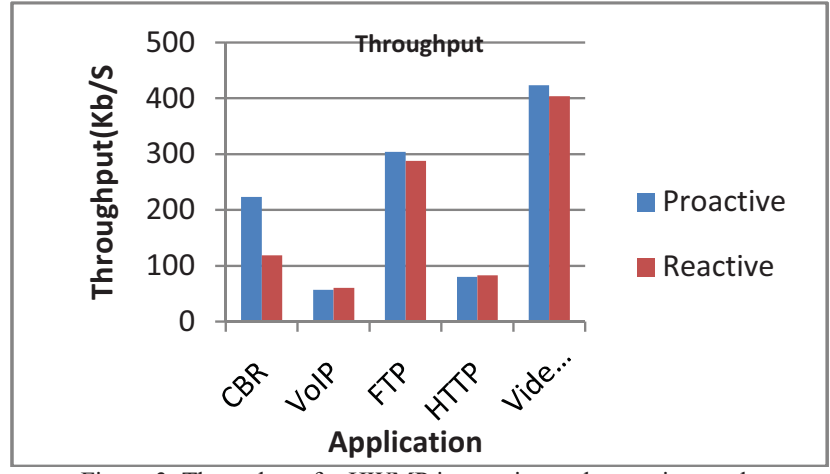

Figure 3. Throughput for HWMP in reactive and proactive mode

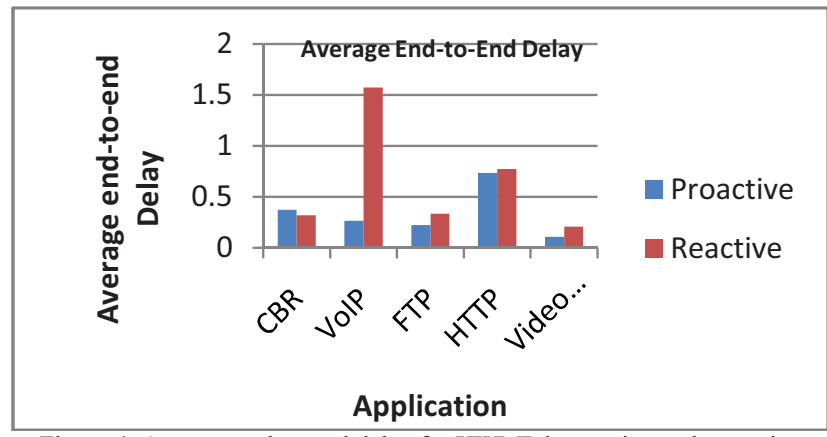

Figure 4. Average end-to-end delay for HWMP in reactive and proactive mode

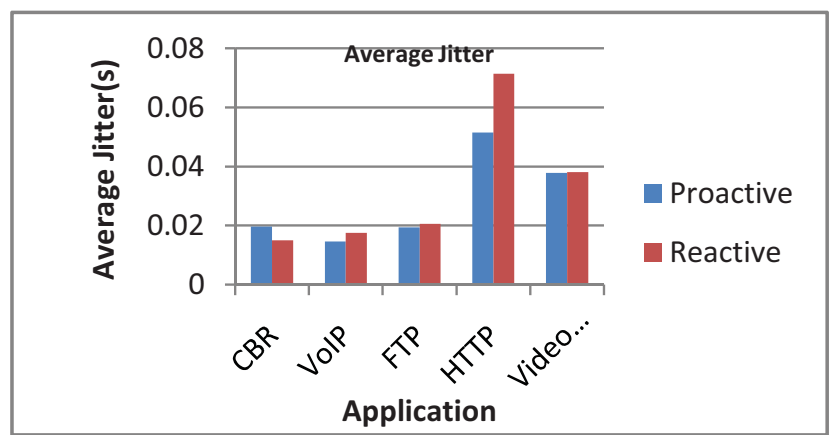

Figure 5. Average jitter for HWMP in reactive and proactive mode

\section{RESUlT AND DISCUSSION}

A number of simulations have been done to explore the performance of HWMP protocol for wireless internet access. Five different types of applications used with different packet size and data rate. All data traffic is either from source node to gateway (root node) or from gateway to source node. This is because to mimic the scenario of typical internet access in wireless environment. According to simulation, throughput of the Proactive PREQ is higher than reactive part for all application type except VoIP.

For average end-to-end delay, Proactive PREQ is shows better performance compared to Reactive (On-demand) part. For VoIP, Proactive PREQ shows almost $80 \%$ less delay than Reactive HWMP. The trend is also same for jitter. Proactive PREQ shows low jitter for all application except CBR which is very important especially for real time application. 
This is because, for proactive PREQ, the path is already established before any data traffic send. On contrary, Reactive HWMP, path is established is on-demand. So the average delay, jitter and throughput performance is better in Proactive PREQ. However, the application is affect each other. The routing protocol does not consider the application type rather based on destination address. The performance of HWMP can be improved by considering application type at the time of path selection.

\section{CONCLUSION}

In this paper, we have been simulated HWMP protocol using Qualnet network simulator. From the simulation result, it is evident that when most of the traffic is from and towards internet, HWMP Proactive PREQ method performs better than Reactive (on-demand) method in terms of throughput, average end-to-end delay and jitter. In future, we will investigate more details on the impact of different application type on routing protocol using different routing metrics and integrate the feature that consider application type for path selection decision.

\section{REFERENCES}

[1] W. Zhang, Z. Wang, S. K. Das, and M. Hassan, Wireless Mesh Networks: Architectures and protocols. New York: Springer, 2008

[2] F. Akyildiz and X. Wang, "Wireless Mesh Networks: A Survey," Computer Networks and ISDN Systems, Vol. 47, No. 4, 2005, pp. 445-487.

[3] IEEE TGs, Status of Project IEEE 802.11s, 2011. http://www.ieee802.org/11/Reports/tgs_update.htm

[4] M. Bahr, "Update on the Hybrid Wireless Mesh Protocol of IEEE 802.11s," IEEE Conference on Mobile Adhoc and Sensor Systems, Pisa, 2007, pp. 1-6.

[5] M. Bahr, "Proposed Routing for IEEE 802.11s WLAN Mesh Networks," The 2nd Annual International Wireless Internet Conference, Boston, 2006, pp. 6-13.

[6] MS Islam, MM. Alam, Md. Abdul Hamid,EFT: a high throughput routing metric for IEEE $802.11 \mathrm{~s}$ wireless mesh networks, Annals of Telecommunications Volume 65, Numbers 5-6, 247-262,2010.

[7] Malte Cornils, Michael Bahr, Thomas Gamer,Simulative Analysis of the Hybrid Wireless Mesh Protocol (HWMP), European Wireless Conference, 2010
[8] Yu-Jin Son, Sung-Hee Lee and Young-Bae Ko, "Session-oriented Adaptive Routing for Improving Path Stability in WLAN based Mesh Networks," 13th International Conference on Advanced Communication Technology (ICACT) 2011, Phoenix Park, Korea, Feb. 2011.

[9] B. Nassereddine, A. Maach, S. Bennani, The Scalability of The Hybrid Protocol in Wireless Mesh Network 802.11s, Mediterrannean Microwave Symposium (MMS), 2009.

[10] Microsoft Research, Self organizing Wireless Mesh Networks. URL http://research.microsoft.com/en-us/projects/mesh/.

[11] Firetide networks, www.firetide.com

[12] MIT roofnet, http://pdos.csail.mit.edu/roofnet/doku.php

[13] Johnson D., Maltz D., Jetcheva J., The dynamic source routing protocol for mobile ad hoc networks for IPv4, RFC4728, Feb 2007

[14] Das S., Perkins C., Royer E., Ad hoc on demand distance vector (AODV) routing, RFC 3561, July 2003.

[15] Abolhasan M., Wysocki T. and Lipman J., Performance Investigation on three-classes of MANET Routing Protocols, in the proceedings of AsiaPacific Conference on Communications, 03-05 Oct. 2005 Page(s):774 778

[16] Guido r. Hiertz, Dee Denteneer, IEEE 802.11S: THE WLAN MESH STANDARD,IEEE Wireless Communications • February 2010

[17] D.S.J.D. Couto, D. Aguayo, J. Bicket and R. Morris. A high-throughput path metric for multi-hop wireless routing. In MobiCom'03: Proceedings of the 9 the annual international conference on Mobile computing and networking, pages134-146, New York, NY, USA, 2003.

[18] R.Draves, J.Padhye, and B.Zill. Routing in multi-radio, multi-hop wireless mesh networks. In MobiCom'04: Proceedings of the 10th annual international conference on Mobile computing and networking, pages114-128, NewYork, NY, USA, 2004.

[19] Y.Yang, J.Wang, and R.Kravets. Load-balanced routing for mesh networks. SIGMOBILE Mob.Comput.Commun.Rev. 10(4):3-5,2006.

[20] Adya A,Bahl P, Padhye J,Wolman A and Zhou L 2004 A multi-radio unification protocol For IEEE802.11 wireless networks. In Proc. Annual International Conferences on Broadband Networks (BroadNets).

[21] R. Draves, J. Padhye and B. Zill, Comparisons of routing metrics for static multi-hop Wireless Networks. In Proc.ACM Annual Conference of the Special Interest Group on Data Communication (SIGCOMM), pp.133-144. 2004

[22] Arafatur Rahman, Saiful Azad, Farhat Anwar, Integrating Multiple Metrics to Improve the Performance of a Routing Protocol over Wireless Mesh Networks, International Conference on Signal Processing Systems, 2009.

[23] Qualnet-5.1 network simulator http://www.scalable-networks.com/ 